\title{
Sustainability in cities: the green areas and climatic comfort as fundamental parameters
}

\author{
F. Gómez, V. Sifre, L. Montero, V. De Vicente \& L. Gil \\ Department of Architectonics Construction, \\ Polytechnic University of Valencia, Valencia, Spain
}

\begin{abstract}
This paper describes the methodology developed by the authors to analyze the influence of "green areas" on the urban comfort of the city of Valencia, taken as the prototype of Mediterranean cities. Based on the analysis of its climatologic conditions, different "comfort indices" are used to study several characteristic districts of the city of Valencia which globally define the urban behaviour of this city. Some of these comfort indices have been formulated in terms of the existing green areas; the results obtained permit one to estimate the amount of the green area required in each district to be considered theoretically comfortable. This methodology can be very useful to urban planners in the design and distribution of green areas in cities.

The study has been completed with a simultaneous survey on human perception of thermal control.

The main conclusion is that green zones play an important role in the thermal comfort of the city and therefore they can be considered one of the most important aspects to take into account in the analysis of urban sustainability.

Keywords: urban climate, green zones, urban planning, urban comfort, sustainability, human perception, Valencia (Spain).
\end{abstract}

\section{Introduction}

Most of the world's population lives in big cities. Man's activities have dramatically changed the environmental and climatic characteristics of the urban areas. This particular phenomenon has been extensively studied in the literature and many works have been developed to analyze the factors that affect human comfort in big cities [1]. 
Solar radiation is one of the most important sources of heat for the human body, in particular when the body is directly exposed to the long wavelength reradiation emitted by surrounding objects; therefore solar radiation is considered as an essential magnitude to calculate the energy balance of the human body in the analysis of human comfort.

On the other hand, green spaces in cities alter some climatic characteristics, acting as correctors or moderators of the environmental variables and improving the conditions of human comfort.

Many studies have proved that green zones not only have ornamental or landscaping functions, but they also play an important role in creating human comfort [2] by improving climatic conditions, acting as coolers and regulators of the air and temperature exchange.

One of the first attempts to accurately define climatic comfort was the work by Max Sorre (1934), who related human comfort with urban microclimate and with the alterations in the climatic conditions resulting from human activities.

Since then, many researchers have developed different models and methods in an attempt to calculate in an objective way the human perception of thermal comfort; that is, not only the climatic parameters of air temperature and relative humidity, but also the actual human perception of the climatic parameters and people's thermal sensation have been used to determine the relationship between thermal environment and behavioural patterns.

The quantification of human thermal comfort is a complex task as any model developed for that end must find a balance between the physiological and biological characteristics of human body and the environmental and climatic variables. In practice, all these variables act together on the organism, each one modifying the effects of the others, and not independently, as reflected by conventional models.

The heat balance of the human body consists of maintaining the body temperature between 36.5 and $37^{\circ} \mathrm{C}$; higher or lower temperatures cause discomfort; at temperatures higher than $40^{\circ} \mathrm{C}$ blood circulation problems start appearing, and over $41-42^{\circ} \mathrm{C}$ coma or total collapse may occur.

To maintain this balance the following equation has to be satisfied:

where:

$$
0=\mathrm{M} \pm \mathrm{R} \pm \mathrm{Cv} \pm \mathrm{Cd}-\mathrm{E}
$$

M Metabolic heat

$\mathrm{R}$ Heat exchange through radiation.

$\mathrm{Cv}$ Heat exchange through convection.

Cd Heat exchange through conduction.

E Loss of heat through evaporation.

Bioclimatologic studies analyze human thermal sensation trying to find scalable parameters for the quantification of human comfort and human response to certain specific climatic conditions. In this sense, different comfort indices have been developed for the quantification of human comfort that include different biological, physical and environmental parameters.

In this work the following indices have been used: 


$$
\begin{aligned}
& \mathrm{ID}=0.4(\mathrm{Ts}+\mathrm{Th})+4.8 \\
& \mathrm{WBGT}=0.7 \mathrm{Th}+0.2 \mathrm{Tg}+0.1 \mathrm{Ts} \\
& \mathrm{PE}=0.57 \mathrm{~V}^{0.42}(36.5-\mathrm{Ts}) 36
\end{aligned}
$$

where: ID Discomfort index [3].

WBGT Wet-Bulb Globe Temperature [4].

PE Vinje's cooling power [5].

Ts Dry bulb temperature $\left({ }^{\circ} \mathrm{C}\right)$

Th Wet-bulb temperature $\left({ }^{\circ} \mathrm{C}\right)$

Tg Dark-bulb or globe temperature $\left({ }^{\circ} \mathrm{C}\right)$

$\mathrm{V}$ Wind speed $\left(\mathrm{m} . \mathrm{s}^{-1}\right)$

The aim of this work was to calculate the value of the meteorological variables using the comfort indices mentioned above. And then to verify the performance of each of these comfort indices in the city of Valencia. For this second aim, the results were compared with a real characterisation of the city, taken as a prototype of the cities of the Mediterranean area.

Finally, we present a modified version of the comfort indices developed by other authors $[6,7]$ in which we have included some objectively quantifiable parameters relative to the effects of green spaces on thermal comfort in cities. The model has been applied to the city of Valencia and results are presented in the second part of this paper.

For that end, we have developed a bioclimatic characterization of the city including all the parameters that may affect human thermal sensation. Finally we analyze the results of perceived thermal comfort obtained using the modified version of the comfort indices.

Basically, the comfort values were formulated using the comfort zones of Olgyay's Chart, [8] taking into account the modifications made to the original by Asharae-Ksu [9]; and the modifications introduced by us for the city of Valencia [10].

The need to assess thermal comfort as a function of green zones finds growing support in the well-known fact that the presence of vegetation is a form of microclimatic control in urban spaces that alters the energy balance of the climate on a local scale, reducing radiant temperature, affecting wind velocity, and altering air temperature and relative humidity.

This microclimatic interaction between the built environment and vegetation helps improve human sensation of comfort in outdoor urban spaces, as well as reduces the effects of climate on buildings.

\section{Methodology}

A total of eight districts of the city of Valencia were used in the study for the field measures. The districts were chosen to be representative of the different microclimates of the city.

The districts selected for the study include the most densely populated districts (2 and 6) and also those districts that presented certain urban and 
environmental peculiarities: outskirts (4 and 10), market gardens (7, 17 and 19) and the sea front (11) [11].

The climatic parameters measured were air temperature (dry and humid), ambient temperature and wind speed.

The air temperature was recorded with a conventional aspirosichrometer, for measuring dry and humid air at the same time; the relative humidity was obtained with the aid of the previous temperatures and psychrometric tables.

Ambient temperature was recorded with a "dark-bulb thermometer"; its measurement, after being left standing for ten minutes, records a temperature which is a combination of the air temperature, direct solar radiation and the amount of radiation received from the surroundings by convection; in our case this measurement was always taken with direct exposure to sunlight. The other measurements were taken in the shade; to avoid the influence of the environment; the measurements were taken two metres away from any facade and at least one metre from ground level.

The wind speed was measured with a Clima Hies digital anemometer, with a range of measurements between 0.1 and $35 \mathrm{~m} . \mathrm{sec}^{-1}$, a reliability of $0.2 \%$ and an integration capacity for time periods between 1 and 10 seconds. The blades of the anemometer were placed at a height of 1.8 to $2 \mathrm{~m}$, from the ground, and taking the integrated measurement during the stationary time of the dark-bulb thermometer.

\section{Comfort indices}

For the analysis of the comfort indices different climatic and environmental parameters were measured in the sampling areas of the city selected for that end.

The field measurements were taken at different sampling points of each district (from 20 to 25), over a period of time between 10 a.m. and 2.30 p.m.

The field sampling points were chosen to cover different structural and urban features, such as ground surfaces, dimensions, proximity of building constructions, type of cover, etc., in particular street orientation, the presence of vegetable cover and the type of soft/hard pavement.

The application of all the comfort indices to the different districts of the city revealed great differences in thermal comfort on a local, (e.g., between streets of the same district) or district level (e.g., between the surroundings (Market Garden) and the city center), or between "soft" and "hard" ground covers.

For the statistical analysis to be significant, the total number of data per sampling point should be ten. For this reason, the field surveys were performed for a period of 10 seasons (1997-99) (Table 1).

Then, these data were used to calculate the comfort indices for each station of the year and city district.

Table 6 shows an example of the data for the summer season taken in district 2. As it can be observed, the "soft" zones (lawns, earth, low bushes, welloriented streets or streets with trees), especially in the summer, present a value closer to comfort than the "hard" zones (concrete or asphalt paving, tiles, hard earth, badly oriented streets or streets with no trees). 
Table 1: $\quad$ District 2 data of the summer, 1997.

\begin{tabular}{|l|l|l|l|l|l|l|}
\hline DATA LOCATIONS & TIME & Vv & Tg & Th & Ts & HR \\
\hline Glorieta gardens (ficus) & 10.00 & 0.1 & 31.0 & 19.0 & 22.4 & 74 \\
\hline Glorieta gardens (recreations) & 10.15 & 0.1 & 31.8 & 19.2 & 22.8 & 71 \\
\hline Navarro Reverter Street & 10.30 & 0.4 & 31.2 & 19.6 & 24.2 & 65 \\
\hline America Square & 11.00 & 0.2 & 33.8 & 20.0 & 25.2 & 62 \\
\hline Cirilo Amoros Street & 11.15 & 0.2 & 34.6 & 20.2 & 25.2 & 63 \\
\hline Grabador Esteve Street & 11.30 & 0.4 & 35.6 & 19.8 & 24.8 & 62 \\
\hline Gran Via Street (pavement) & 11.45 & 0.9 & 34.0 & 20.8 & 26.2 & 61 \\
\hline Gran Via Street (garden) & 12.00 & 0.6 & 34.8 & 20.2 & 25.2 & 63 \\
\hline Salamanca Street & 12.15 & 0.1 & 36.2 & 21.0 & 26.6 & 60 \\
\hline Ciscar Street & 12.30 & 0.7 & 37.6 & 21.0 & 27.0 & 58 \\
\hline Joaquin Costa Street & 12.45 & 0.4 & 39.8 & 21.4 & 26.8 & 62 \\
\hline Burriana Street & 13.00 & 0.5 & 37.2 & 20.4 & 27.0 & 55 \\
\hline Dña. Germana King Street & 13.15 & 0.9 & 37.8 & 21.2 & 26.8 & 61 \\
\hline Regne de Valencia Avenue & 13.30 & 1.3 & 36.4 & 21.6 & 27.0 & 62 \\
\hline Matias Perello Street & 13.45 & 0.8 & 36.4 & 22.0 & 26.8 & 66 \\
\hline Peris y Valero Street & 14.00 & 1.2 & 37.8 & 21.4 & 27.2 & 60 \\
\hline
\end{tabular}

Vv Wind speed $\left(\mathrm{m} \cdot \mathrm{s}^{-1}\right)$

Tg Dark-bulb or globe temperature $\left({ }^{\circ} \mathrm{C}\right)$

Th Wet-bulb temperature $\left({ }^{\circ} \mathrm{C}\right)$

Ts Dry bulb temperature $\left({ }^{\circ} \mathrm{C}\right)$

Hr Relative humidity (\%)

For clarity, the comfort values were coloured with different color intensities (see diagram below), depending on whether the value lies under (white), within (light grey) or above (dark grey) the lower and higher comfort limits (Table 2).

\begin{tabular}{|l|l|l|}
\hline Cold & Comfortable & Hot \\
\hline
\end{tabular}

Table 2: $\quad$ Comfort ranges of each index.

\begin{tabular}{|l|c|c|c|}
\hline INDEX & Cold & Comfortable & Hot \\
\hline ID & $<14.16$ & 14.16 to 26.4 & $>26.4$ \\
\hline VINJE & $>10$ & 10 to 5 & $<5$ \\
\hline WBGT & $<58.86$ & 58.86 to 88.31 & $>88.31$ \\
\hline
\end{tabular}

Table 3 illustrates the results obtained in district 2 with the different comfort indices used in this study. 
Table 3: $\quad$ Results of the indices for district 2.

\begin{tabular}{|l|c|c|c|c|}
\hline DATA LOCATIONS & TIME & ID & VINJE & WBGT \\
\hline Glorieta gardens (ficus) & 10.15 & 13.32 & 5.24 & 53.51 \\
\hline Glorieta gardens (recreations) & 10.30 & 13.4 & 5.2 & 54.62 \\
\hline Navarro Reverte Street & 10.45 & 13.72 & 9.46 & 54.91 \\
\hline America Square & 11.00 & 13.88 & 6.57 & 55.74 \\
\hline Cirilo Amoros Street & 11.15 & 14.84 & 5.54 & 57.14 \\
\hline Grabadpr Esteve Street & 11.30 & 14.4 & $\mathbf{4 . 8 5}$ & 56.58 \\
\hline Gran Via Street (pavement) & 11.45 & 14.84 & 6.89 & 57.97 \\
\hline Gran Via Street (garden) & 12.00 & 14.88 & 7.95 & 58.17 \\
\hline Salamanca Street & 12.15 & 15.04 & 6.74 & 58.1 \\
\hline Ciscar Street & 12.30 & 15.08 & 7.35 & 58.73 \\
\hline Joaquin Costa Street & 12.45 & 15.24 & 4.59 & 59.19 \\
\hline Burriana Street & 1.00 & 15.44 & 4.53 & 59.18 \\
\hline Dña. Germana King Street & 1.15 & 15.6 & $\mathbf{4 . 4 4}$ & 59.43 \\
\hline Regne de Valencia Avenue & 1.30 & 15.84 & 6.91 & 60.58 \\
\hline Matias Perello Street & 2.00 & 15.84 & 7.79 & 60.29 \\
\hline Peris y Valero Street & 2.15 & 16.4 & 7.32 & 62.17 \\
\hline
\end{tabular}

As can be observed in the table, the distinction between cold, comfortable or hot points in the sampling areas greatly depends on the type of ground pavement (hard or soft) existing in the zone.

Since the authors of the conventional comfort indices base their analysis on other environmental parameters [6], and in view of the results obtained in this study, we consider that a more reliable and accurate model of thermal comfort should include green zone parameters [12].

In the revision of the exiting literature on the topic we found one study in which reference is made to this relationship between the dimensions of green spaces and environmental improvement in thermal comfort [13].

This author gives an estimated surface area of $10 \mathrm{Ha}$. to obtain a reduction in air temperature of $1^{\circ} \mathrm{C}$.

Therefore, we believe that the results obtained in our study did not correlate well because the size of the green zones in the districts of the city was too small to influence the estimation of the comfort indices. For this reason, we have reformulated the concept of green areas using the terms of soft of hard zones instead.

We then calculated again the values of each comfort index including this time the new concept of hard/soft zone. The results of the indices showed a good agreement with the field measurements, and in $100 \%$ of the cases the "soft" 
zones of the sampling districts displayed values closer to comfort (Figure 1, Table 4).

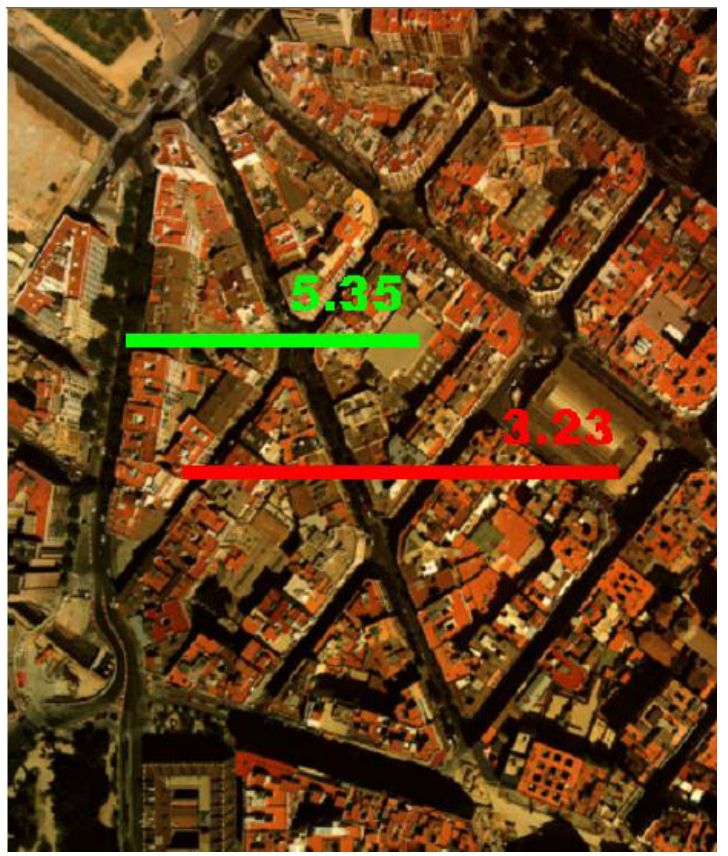

Figure 1: Grabador Esteve and Navarro Reverter Streets (comfort values between 5 and 10, under 5 this is hot).

Table 4: $\quad$ Formulation of the WBGT index for Valencia.

\begin{tabular}{|c|c|}
\hline \multicolumn{2}{|c|}{ Formulation of the Radiant wet bulb temperature index for Valencia } \\
\hline Autumn & $\begin{array}{c}\text { WBGT }=38,29 \mathrm{~B}+39,07 \mathrm{D}+1,81 \mathrm{H} \\
\left(\mathrm{R}^{2}=99.30\right)\end{array}$ \\
\hline Spring & $\begin{array}{c}\text { WBGT }=59,07 \mathrm{~B}+58,99 \mathrm{D}+1,16 \mathrm{H} \\
\left(\mathrm{R}^{2}=99.70\right)\end{array}$ \\
\hline Summer & $\begin{array}{c}\text { WBGT }=67,98 \mathrm{~B}+68,73 \mathrm{D}+1,03 \mathrm{H} \\
\left(\mathrm{R}^{2}=99.00\right)\end{array}$ \\
\hline Winter & $\begin{array}{c}\text { WBGT }=36,66 \mathrm{~B}+37,39 \mathrm{D}+1,73 \mathrm{H} \\
\left(\mathrm{R}^{2}=98.00\right)\end{array}$ \\
\hline
\end{tabular}

The Coefficients of Determination obtained are considerably higher than those reported in other works [7] (Table 5).

The good results obtained with this new approach allowed us to successfully reformulate the comfort indices for the city of Valencia [14]. 
Table 5: Comparison between Coefficients of Determination obtained in Seoul and Valencia.

\begin{tabular}{|l|c|c|}
\hline Coef. of Determination Statistic. & Seoul & Valencia \\
\hline Standard error & 1.213 & 1.183 \\
\hline Coef. Determination $\left(\mathrm{R}^{2}\right)$ & 0.35 & 0.99 \\
\hline F value & 0.0419 & 0.0023 \\
\hline
\end{tabular}

\section{Analysis of human thermal perception}

Together with the analysis of the climatic and biological parameters used to calculate the comfort indices for the city of Valencia, a survey of human thermal perception was performed at the same hours, districts and streets as the climatic data used in the scientific analysis.

The purpose of the survey was to compare the opinion of the residents with the results obtained from the climatic data recorded in the different districts of the city. In this way, we could find the comfort index (from the comfort indices analyzed in this work) that best fitted the thermal comfort perception of the people living in those districts. For that end, we compared the graphs obtained for each comfort index with those obtained from the citizen's survey.

\subsection{Characteristics of the human perception analysis}

The survey was performed in the 9 districts analyzed and the sample included people over 14 of both genres.

The maximum error limit of the survey was $\pm 2.6 \%$, with a confidence level of $95 \%$ for values of $\mathrm{p}=\mathrm{q}=0.50$, and the total size of the sample was 1,500 people.

The sample data correspond to the different districts and seasons of the year, and the total number of persons interviewed is shown in Table 6.

The survey was performed at the same hours and sites as the recorded climatic data, so that the answers of the interviewed people were in accordance with the data used in the scientific analysis

Table 6: $\quad$ Number of interviewed people for each season of the year.

\begin{tabular}{|l|c|}
\hline \multicolumn{1}{|c|}{ SEASON } & INTERVIEWED PERSONS \\
\hline Spring & 378 \\
\hline Summer & 348 \\
\hline Autumn & 397 \\
\hline Winter & 309 \\
\hline
\end{tabular}

The error produced in the analysis of the survey data per seasons is approximately $\pm 5 \%$, with a confidence level of $95 \%$.

The questionnaire was designed and analyzed by the staff of the Department of Statistics of the Polytechnic University of Valencia. 


\subsection{Results of the human perception analysis}

Table 7 presents the survey results about comfort and discomfort data as perceived by the interviewed people, for each season of the year in the city of Valencia.

Table 7: Percentage of interviewed people giving their opinion about comfort and discomfort for each season of the year.

\begin{tabular}{|l|c|c|}
\hline SEASON & COMFORT & DISCOMFORT \\
\hline Spring & $0.1 \%$ & $85.1 \%$ \\
\hline Summer & $25.9 \%$ & $40.3 \%$ \\
\hline Autumn & $5.4 \%$ & $73.3 \%$ \\
\hline Winter & $12.4 \%$ & $56.3 \%$ \\
\hline
\end{tabular}

This general opinion is in agreement with the districts that, particularly in autumn and spring lie in the comfort zone; very few districts are in the cold zone and even fewer in the hot zone, similarly to the results obtained after applying Vinje's comfort index (PE) [11].

The people's opinion, presented in Table 7, clearly shows that summer is the least desirable season, especially for women, as the survey data indicate.

If we observe the graph obtained from the survey data (Fig.2), we can see that there are very few districts in which the residents feel uncomfortable.

The districts considered as uncomfortable by the residents are:

In summer, District 2 is considered to be hot (the district most typically urban, with a grid-like urban planning and narrow streets with trees that, on one hand prevent solar radiation, but on the other prevent refreshing wind flow in this season); for the same reasons, districts 7 and 10 are considered hot districts by the residents.

In winter, District 10 is considered to be cold due to the fact that it is much more open than District 2 and therefore it has streets which allow the flow of cold winds; in addition, Districts 17 and 19, located at the North and South of the city, are also considered to be cold as they are much more exposed to the cold NE winds.

To conclude, we can say that the climatic comfort index that best expresses the residents' climatic perception in the different districts analyzed is the WBGT comfort index, as a general index; and if wind factor is taken into account, then Vinje's comfort index will provide better results (the former for microspaces, and the latter for macrospaces, for example, districts).

Although the climatic data of the scientific research were in agreement with the data obtained from the survey, the small differences observed come from the fact that one thing is the meteorological measurement and mathematical calculation of thermal comfort, and another thing is the citizen's comfort perception, which is affected by factors such as age, genre, health, mood, etc., factors that clearly a mathematical equation cannot provide. 

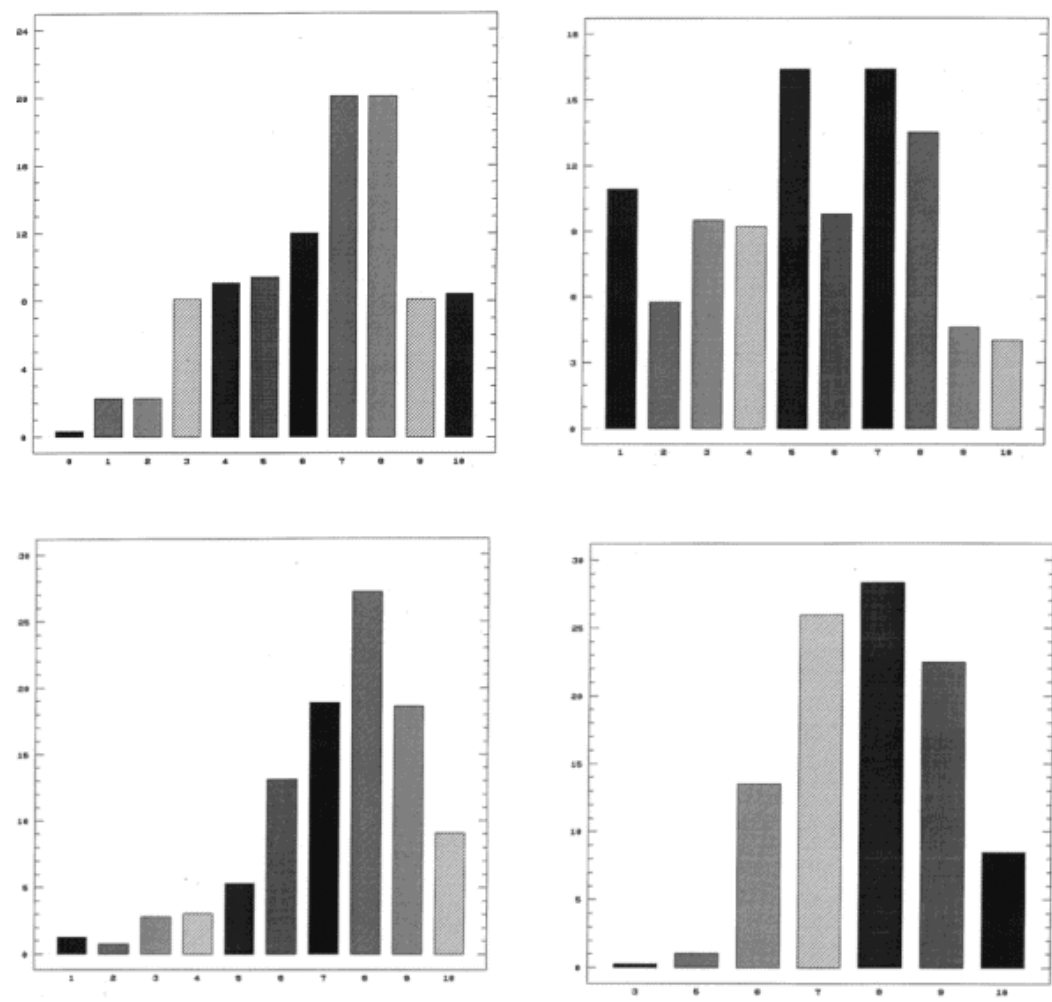

Figure 2: Climatic comfort sensation in the four season or the year, spring, summer, winter and autumn, according to the answers of the interviewed people $(\mathrm{Y}$ axis $=$ percentage of answers and $\mathrm{X}$ axis $=$ value (from 1 to 10 ) of the answers).

\section{Conclusions}

The city of Valencia was the scenario for this research, taken as a prototype of Mediterranean cities because of its typical Mediterranean climatic conditions.

In this study we used different conventional comfort indices adapted to the city of Valencia. The mathematical model included the effects of the green zones on the comfort values. For a more reliable and accurate calculation of the index, a new concept of hard/soft zone has been developed that provides a more close approximation to the real comfort values of the field survey.

This reformulation of the comfort index using the concept of "hard" and "soft" zones may be used as a powerful tool by urban planners in the design of open areas, in particular in cities with a warm climate and a high number of hot days per year, like in Valencia. 
The thermal comfort index developed by the authors in this work for the city of Valencia can be extrapolated to other cities of the Mediterranean area that present similar climatic characteristics.

Future studies can be conducted to further our understanding of the thermal comfort in open spaces, mainly in warn climate cities where summer conditions are critical.

Together with the scientific research, a survey of human thermal sensation has been conducted in the same urban space. The results show a close correlation between people's thermal sensation and the values of the comfort index.

\section{References}

[1] Oke, T. R. (1990) Boundary layer climates, $2^{\text {a }}$ Ed. Boutledge, London.

[2] Werner, P. and Sukkopp, H. (1982) Nature in cities, Council of Europe, Strasbourg

[3] Thom, E.C. (1959) The discomfort index, Weatherwise, 12:57- 60.

[4] Watson, D. and Labs, K (1983) Climatic Design, Energy-Efficient Building Principles and Practices, McGraw-Hill Book Company, New York.

[5] Landsber, H.E. (1981) The Urban climate, New York Academic Press, pp.275.

[6] Salvador, P. J. and Smith, D.R. (1987) Vegetation and urban climate in Valencia, Spain, A pilot Project, Mab-Unesco, pp. 125.

[7] Kwi-Gon-Kim., (1989) Climate, Urbanization and green spaces in urban areas, the case of Seoul, Mab-Unerso, University of Seoul.

[8] Olgyay, V. (1973) Design with climate, Princeton Univ. Press. 190 pp.

[9] Rholes, F.H. Jr. (1980) The preferred Indoor Comfort Temperatures (Report No 80-02, Institute for Environment Research, Kansas State University, Manhattan, Ks.

[10] Gómez, F., Tamarit, N. and Jabaloyes, J. (1999) Bioclimatic Characterization of the Mediterranean City: The Valencian case, PLEA'99, Ed. Steven Szokolay, Brisbane, pp. 807-812.

[11] Gómez, F. Gil, L., Montero, L. and V. De Vicente. (2004) Climate indicators for cities. The Sustainable City III. Urban Regeneration and Sustainability. WIT Press, July, SIENA (Italy), pp. 91-102.

[12] Gómez, F. M.L. Gil, Montero, L. and F. Rodrigo (2002) The Green zones, main factor of urban regeneration and of city sustainability, The Sustainable city II, WIT Press, July, Segovia (Spain), pp. 315-324

[13] Sthülpnagel, A. (1987) Klimatisce Veränderungen in Ballunngsgebieten unter besonderer Berüchschtingug der Ausgleichaswirkung vonGrünflächen, dargestellt am Beispiel von Berlin (West). Diss. FB 14, TU, Berlin.

[14] Gomez, F., Montero, L., Jabaloyes, J, and Salvador, P. (2000) The Green zones like model of infrastructure in the urban development toward the sustainability, WIT Press, July, Alicante (Spain), pp. 185-194. 